\title{
Influence of unilateral intravitreal bevacizumab injection on the incidence of symptomatic choroidal neovascularization in the fellow eye in patients with neovascular age-related macular degeneration (Review)
}

\author{
DANIEL CONSTANTIN BRANISTEANU ${ }^{1,2^{*}}$, DACIANA ELENA BRANISTEANU ${ }^{3}$, CRENGUTA IOANA FERARU $^{1,2}$, \\ CATALINA IOANA BRANISTEANU ${ }^{4 *}$, ANDREEA MORARU ${ }^{1 *}$, MIHAIL ZEMBA $^{5}$ and FLORIAN BALTA ${ }^{5}$ \\ ${ }^{1}$ Department of Ophthalmology, 'Grigore T. Popa' University of Medicine and Pharmacy, 700115 Iasi; \\ ${ }^{2}$ 'Retina Center' Eye Clinic, 700126 Iasi; ${ }^{3}$ Department of Dermatology, 'Grigore T. Popa' University \\ of Medicine and Pharmacy; ${ }^{4}$ 'Grigore T. Popa' University of Medicine and Pharmacy, 700115 Iasi; \\ ${ }^{5}$ Department of Ophthalmology, 'Carol Davila' University of Medicine and Pharmacy, 020021 Bucharest, Romania
}

Received May 15, 2020; Accepted June 16, 2020

DOI: $10.3892 / \mathrm{etm} .2020 .9312$

\begin{abstract}
Neovascular age-related macular degeneration (neovascular ARMD) represents only $10 \%$ of ARMD cases but is responsible, if untreated, for quick and severe central vision loss due to major macular changes. The presence of choroidal neovascularization (CNV) in one eye is associated with an approximately $10 \%$ risk of CNV development in the fellow eye each year. Intravitreal anti-VEGF therapy has quickly evolved as the standard treatment in neovascular ARMD in the last decade due to significant anatomical and functional improvements, especially in the early stages. In many reports an improvement in the untreated fellow eye was mentioned and systemic exposure was soon confirmed for all anti-VEGF agents after unilateral intravitreal injection. In particular, bevacizumab intravitreal injection is followed by a consistent reduction of serum VEGF levels and the drug was shown to have the longest serum half-life raising important debates about its safety. Once bevacizumab was detected in the fellow
\end{abstract}

Correspondence to: Professor Daciana Elena Branisteanu, Department of Dermatology, 'Grigore T. Popa' University of Medicine and Pharmacy, 16 University Street, 700115 Iasi, Romania

E-mail: debranisteanu@yahoo.com

Professor Mihail Zemba, Department of Ophthalmology, 'Carol Davila' University of Medicine and Pharmacy, 37 Dionisie Lupu Street, 020021 Bucharest, Romania

E-mail: mhlzmb@yahoo.com

*Contributed equally

Key words: symptomatic choroidal neovascularization, fellow-eye, bevacizumab, neovascular age-related macular degeneration, systemic exposure eye of an animal model after unilateral injection, the possible influence on fellow eye conversion rate into neovascular ARMD was questioned. Although comparative studies have not found statistically significant differences between drugs regarding the incidence of symptomatic CNV in the fellow eye during treatment, we observed, on a retrospective 36-month evaluation, a reduced incidence of symptomatic CNV in the fellow eye that might be explained by the consistent systemic exposure of bevacizumab.

\section{Contents}

1. Introduction

2. The current state of knowledge regarding the systemic exposure and the influence of unilateral intravitreal anti-VEGF injection on the fellow eye

3. Conclusions

\section{Introduction}

Age-related macular degeneration (ARMD) is the leading cause of severe, irreversible central visual loss in elderly people, especially in developed countries (1). The prevalence of ARMD significantly increases after the age of 50 with each decade (2). Also, there is a marked tendency for worldwide increasing incidence. Although neovascular ARMD accounts for only $10 \%$ of the cases, its presence is associated with a faster and worse prognosis due to metamorphopsia and significant loss of central vision. Due to their remarkable ability to quickly improve symptoms and also to provide consistent visual recovery, intravitreal administration of different anti-VEGF agents is nowadays the standard treatment for many retinal diseases including neovascular ARMD, diabetic retinopathy, diabetic macular edema, venous occlusions and other retinal disorders (3). Ranibizumab (Lucentis ${ }^{\circledR}$ ) and 
Aflibercept $\left(\right.$ Eylea $\left.^{\circledR}\right)$ are FDA and EMA approved for intravitreal use in neovascular ARMD and recently Brolucizumab $\left(\right.$ Beovu $\left.^{\circledR}\right)$ received both approvals for this indication. Although multiple studies have confirmed the comparable efficacy and safety of intravitreal bevacizumab (Avastin ${ }^{\circledR}$ ) administration to registered anti-VEGF drugs (4-9), bevacizumab continues to have an off-label status. A recent study evaluating bevacizumab use in 20 European countries showed that a consensus on the ophthalmic off-label use of bevacizumab in Europe has not yet been reached and member states have different approaches (10). Bevacizumab intravitreal injections quota significantly varies in different European countries and even developed economies use bevacizumab after informed consent is obtained. In the USA, the majority of retina specialists are using bevacizumab as the first-line drug (11). Thus, due to its worldwide massive use, mainly related to the significantly lower price, bevacizumab is considered to be the most cost-effective drug for neovascular ARMD (12-15).

\section{The current state of knowledge regarding the systemic exposure and the influence of unilateral intravitreal anti-VEGF injection on the fellow eye}

As in many retinal diseases, one key problem in neovascular ARMD is the fellow eye involvement. Literature data largely vary on this topic. In clinical trials fellow eye involvement was noted at 22,24 and $36.3 \%$ of patients by 24 months (16-18), regardless of the medication. A recent real-life evaluation reported a $32 \%$ fellow eye involvement rate at two years (19). Severe macular changes in the affected eye (larger membranes, more intraretinal fluid) in addition to increased age, female sex and genetic disposition correlate to a higher risk of second eye involvement $(18,20)$. Optical coherence tomography angiography (OCTA) evaluation suggests that the presence of subclinical CNV in fellow-eye is associated with an increased risk of exudation $(21,22)$.

Another key problem is the influence of anti-VEGF treatment in one eye on the fellow eye that has no clinical signs of neovascularization at baseline. Post hoc analysis of some major randomized, double-masked, active-controlled, multicenter clinical trials could not reveal any consistent influence of intravitreal ranibizumab or aflibercept injections on fellow eye conversion rates $(17,18)$. When studying bevacizumab, also, no difference was noted in the first study year $(7.2 \%$ of patients treated with bevacizumab vs. $7.9 \%$ of patients treated with ranibizumab). After 2 years, a difference was noted, although not statistically significant $(16.6 \%$ of patients treated with bevacizumab vs. $20.6 \%$ of patients treated with ranibizumab (23). These results can be explained, at least in part, by the systemic exposure and the significantly longer reduction of VEGF serum levels after intravitreal injections of bevacizumab. A consistent reduction in human serum VEGF levels has been observed after intravitreal injections of all anti-VEGF agents but more prominent after the use of aflibercept and bevacizumab $(24,25)$. Different human studies have focused on establishing the systemic half-life of anti-VEGF agents injected intravitreally $(26,27)$. In the case of ranibizumab, the systemic half-life was estimated at $2 \mathrm{~h}$ after one injection and 5.8 days after 3 injections of $0.5 \mathrm{mg}$. The serum half-life of aflibercept is estimated at 11.4 days after three-monthly intravitreal injections of $2.0 \mathrm{mg}$ while bevacizumab has the longest serum half-life, around 18.7 days, after three intravitreal doses of $1.25 \mathrm{mg}$. Both aflibercept and bevacizumab manifest systemic drug accumulation between the first three doses while ranibizumab has the quickest bloodstream clearance that does not allow significant systemic accumulation. These findings are confirmed by the IVAN study, one of the most important trials of the last decade. The analysis of serum VEGF levels in patients with neovascular ARMD revealed a more consistent and long-standing VEGF suppression induced by bevacizumab as compared with ranibizumab (reduction of $69 \%$ for bevacizumab and $20 \%$ for ranibizumab at 1 year, and a reduction of $78 \%$ for bevacizumab and $28 \%$ for ranibizumab at 2 years) (23).

Fellow eye effects due to systemic exposure of bevacizumab have been reported, in real life, from its very early use in many retinal diseases including proliferative diabetic retinopathy, diabetic macular edema, type 2 idiopathic macular telangiectasia, uveitic cystoid macular edema and retinopathy of prematurity (28-30). A recent publication reports a greater therapeutic effect of unilateral bevacizumab in the fellow eye when compared with the other two anti-VEGF agents (31).

In the particular case of neovascular ARMD there are many reports on clinically significant improvements of the untreated fellow eye after unilateral injections of anti-VEGF agents. They concern visual acuity, fluorescein angiography, and/or central macular thickness as measured by spectral-domain optical coherence tomography (SD-OCT) $(32,33)$. In a prospective, non-randomized trial, patients with unilateral neovascular ARMD were treated with intravitreal injection of ranibizumab or bevacizumab and fellow-eye changes of central retinal artery equivalent (CRAE) and central retinal vein equivalent were measured postoperatively using image analysis software. A significant transient narrowing effect on the CRAE was noted in the fellow non-treated eyes of the bevacizumab group only three days after injection (34). This reaction is supposed to be the consequence of bevacizumab interference with nitric oxide production from vascular endothelial cells (35).

If unilateral intravitreal injections of bevacizumab are influencing the conversion rate of the fellow eye in patients with unilateral neovascular ARMD at baseline is still unknown and there is a lack of literature on this topic. After the study approval by the Ethics Committee of 'Retina Center' Eye Clinic (Iasi, Romania), we performed a retrospective, non-comparative analysis on a consecutive group of patients with unilateral neovascular ARMD at baseline, treated with intravitreal bevacizumab exclusively. Informed consent was obtained from each patient. The patients received 3 monthly intravitreal injections of $1.25 \mathrm{mg} / 0.05 \mathrm{ml}$ bevacizumab followed by additional injections on a treat and extend basis, as a part of the current treatment protocol in neovascular ARMD at 'Retina Center' Eye Clinic in Iasi.

After reviewing data from 255 patients followed-up for 36 months, we found that symptomatic CNV developed in 5 fellow eyes at 12 months (3.08\%), 19 fellow eyes at 24 months $(10.55 \%)$ and in 29 fellow eyes at 36 months (17.90\%). These results are somehow intriguing in view of lower incidence as compared with observational large-scale studies involving other anti-VEGF agents and suggest a possible interference of bevacizumab with the fellow eye conversion rate. 


\section{Conclusions}

Until now, the more substantial systemic exposure of bevacizumab after intravitreal injection as compared with ranibizumab and aflibercept has raised challenging discussions concerning only an increased risk of systemic adverse events (especially cerebrovascular accidents) and the interference with VEGF-dependent physiological processes (especially in newborn babies). It also looks very plausible that long-term unilateral intravitreal injections of bevacizumab in neovascular ARMD could prevent the appearance of symptomatic neovascularization in the fellow eye. Whether or not this intriguing effect is significant will be confirmed by larger, comparative studies.

\section{Acknowledgements}

Not applicable.

\section{Funding}

No funding was received.

\section{Availability of data and materials}

The datasets used and/or analyzed during the current study are available from the corresponding author on reasonable request.

\section{Authors' contributions}

DCB and DEB contributed to the design of the study, participated in the entire review process and prepared the manuscript. CIB, AM and CIF contributed to the literature research, and the analysis and critical interpretation of the data. MZ and FB conceived the study and revised the manuscript. All authors read and approved the final version of the manuscript.

\section{Ethics approval and consent to participate}

The study was approved by the Ethics Committee of 'Retina Center' Eye Clinic (Iasi, Romania) and informed consent was obtained from each patient.

\section{Patient consent for publication}

Not applicable.

\section{Competing interests}

All the authors declare that they have no competing interests.

\section{References}

1. Rosenfield PJ, Martidis A and Tennant M: Age-related macular degeneration. In: Ophthalmology: Expert Consult. 3rd edition. Yanoff M, Duker JS and Augsburger JJ (eds). Elsevier Mosby, Philadelphia, PA, 2009.

2. Cheung LK and Eaton A: Age-related macular degeneration. Pharmacotherapy 33: 838-855, 2013.
3. Villegas VM, Aranguren LA, Kovach JL, Schwartz SG and Flynn HW Jr: Current advances in the treatment of neovascular age-related macular degeneration. Expert Opin Drug Deliv 14: 273-282, 2017.

4. Chakravarthy U, Harding SP, Rogers CA, Downes SM, Lotery AJ, Culliford LA and Reeves BC; IVAN study investigators: Alternative treatments to inhibit VEGF in age-related choroidal neovascularisation: 2-year findings of the IVAN randomised controlled trial. Lancet 382: 1258-1267, 2013.

5. Martin DF, Maguire MG, Fine SL, Ying GS, Jaffe GJ, Grunwald JE, Toth C, Redford M and Ferris FL III; Comparison of Age-related Macular Degeneration Treatments Trials (CATT) Research Group: Ranibizumab and bevacizumab for treatment of neovascular age-related macular degeneration: Two-year results. Ophthalmology 119: 1388-1398, 2012.

6. Schauwvlieghe AM, Dijkman G, Hooymans JM, Verbraak FD, Hoyng CB, Dijkgraaf MG, Peto T, Vingerling JR and Schlingemann RO: Comparing the effectiveness of bevacizumab to ranibizumab in patients with exudative age-related macular degeneration. The BRAMD Study. PLoS One 11: e0153052, 2016.

7. Krebs I, Schmetterer L, Boltz A, Told R, Vécsei-Marlovits V, Egger S, Schönherr U, Haas A, Ansari-Shahrezaei S and Binder S; MANTA Research Group: A randomised double-masked trial comparing the visual outcome after treatment with ranibizumab or bevacizumab in patients with neovascular age-related macular degeneration. Br J Ophthalmol 97: 266-271, 2013.

8. Kodjikian L, Souied EH, Mimoun G, Mauget-Faÿsse M, BeharCohen F, Decullier E, Huot L, Aulagner G; GEFAL Study Group: Ranibizumab versus Bevacizumab for neovascular age-related macular degeneration: Results from the GEFAL noninferiority randomized trial. Ophthalmology 120: 2300-2309, 2013.

9. Berg K, Pedersen TR, Sandvik L and Bragadóttir R: Comparison of ranibizumab and bevacizumab for neovascular age-related macular degeneration according to LUCAS treat-and-extend protocol. Ophthalmology 122: 146-152, 2015.

10. Bro T, Derebecka M, Jørstad ØK and Grzybowski A: Off-label use of bevacizumab for wet age-related macular degeneration in Europe. Graefes Arch Clin Exp Ophthalmol 258: 503-511, 2020.

11. American Society of Retina Specialists: Preferences and trends Survey 2018. https://www.asrs.org/content/documents/2018-gl obal-trends-in-retina-survey-highlights-website.pdf. Accessed May 1, 2020.

12. Elshout M, Webers CAB, van der Reis MI and Schouten JSAG: A systematic review on the quality, validity and usefulness of current cost-effectiveness studies for treatments of neovascular age-related macular degeneration. Acta Ophthalmol 96: 770-778, 2018.

13. Low A, Faridi A, Bhavsar KV, Cockerham GC, Freeman M, Fu R, Paynter R, Kondo K and Kansagara D: Comparative effectiveness and harms of intravitreal antivascular endothelial growth factor agents for three retinal conditions: A systematic review and meta-analysis. Br J Ophthalmol 103: 442-451, 2019.

14. Stanca HT, Stanca S, Tabacaru B, Boruga M and Balta F: Bevacizumab in Wet AMD treatment: A tribute to the thirteen years of experience from the beginning of the anti-VEGF era in Romania. Exp Ther Med 18: 4993-5000, 2019.

15. Brănisteanu DC, Munteanu M, Branisteanu DE, Stanca HT, Moraru A and Baltă F: 'Off-Label' drug use - ethical challenges. Case study - AVASTIN ${ }^{\circledR}$. Rev Rom Bioet 13: 170, 2015.

16. Solomon SD, Jefferys JL, Hawkins BS and Bressler NM; Submacular Surgery Trials Research Group: Incident choroidal neovascularization in fellow eyes of patients with unilateral subfoveal choroidal neovascularization secondary to age-related macular degeneration: SST report No. 20 from the Submacular Surgery Trials Research Group. Arch Ophthalmol 125: 1323-1330, 2007.

17. Barbazetto IA, Saroj N, Shapiro H, Wong P, Ho AC and Freund KB: Incidence of new choroidal neovascularization in fellow eyes of patients treated in the MARINA and ANCHOR trials. Am J Ophthalmol 149: 939-946.e1, 2010.

18. Parikh R, Avery RL, Saroj N, Thompson D and Freund KB: Incidence of new choroidal neovascularization in fellow eyes of patients with age-related macular degeneration treated with intravitreal aflibercept or ranibizumab. JAMA Ophthalmol 137: 914-920, 2019.

19. Fasler K, Fu DJ, Moraes G, Wagner S, Gokhale E, Kortuem K, Chopra R, Faes L, Preston G, Pontikos N, et al: Moorfields AMD database report 2: Fellow eye involvement with neovascular age-related macular degeneration. Br J Ophthalmol 104: 684-690, 2020. 
20. Rasmussen A, Fuchs J, Hansen LH, Larsen M, Sander B and Lund-Andersen H: Neovascular age-related macular degeneration: Is it worthwhile treating an eye with poor visual acuity, if the visual acuity of the fellow eye is good? Eye (Lond) 31: 978-980, 2017.

21. de Oliveira Dias JR, Zhang Q, Garcia JMB,Zheng F, Motulsky EH, Roisman L, Miller A, Chen CL, Kubach S, de Sisternes L, et al: Natural history of subclinical neovascularization in nonexudative age-related macular degeneration using swept-source OCT angiography. Ophthalmology 125: 255-266, 2018.

22. Yanagi Y, Mohla A, Lee SY, Mathur R, Chan CM, Yeo I, Wong TY and Cheung CMG: Incidence of fellow eye involvement in patients with unilateral exudative age-related macular degeneration. JAMA Ophthalmol 136: 905-911, 2018.

23. Maguire MG, Daniel E, Shah AR, Grunwald JE, Hagstrom SA, Avery RL, Huang J, Martin RW, Roth DB, Castellarin AA, et al; Comparison of Age-Related Macular Degeneration Treatments Trials (CATT Research Group): Incidence of choroidal neovascularization in the fellow eye in the comparison of age-related macular degeneration treatments trials. Ophthalmology 120 . 2035-2041, 2013.

24. Zehetner C, Kirchmair R, Huber S, Kralinger MT and Kieselbach GF: Plasma levels of vascular endothelial growth factor before and after intravitreal injection of bevacizumab, ranibizumab and pegaptanib in patients with age-related macular degeneration, and in patients with diabetic macular oedema. Br J Ophthalmol 97: 454-459, 2013.

25. Chakravarthy U, Harding SP, Rogers CA, Downes SM, Lotery AJ, Wordsworth S and Reeves BC; IVAN Study Investigators: Ranibizumab versus bevacizumab to treat neovascular age-related macular degeneration: One-year findings from the IVAN randomized trial. Ophthalmology 119: 1399-1411, 2012.

26. Avery RL, Castellarin AA, Steinle NC, Dhoot DS, Pieramici DJ, See R, Couvillion S, Nasir MA, Rabena MD, Le K, et al: Systemic pharmacokinetics following intravitreal injections of ranibizumab, bevacizumab or aflibercept in patients with neovascular AMD. Br J Ophthalmol 98: 1636-1641, 2014.
27. García-Quintanilla L, Luaces-Rodríguez A, Gil-Martínez M, Mondelo-García C, Maroñas O, Mangas-Sanjuan V, GonzálezBarcia M, Zarra-Ferro I, Aguiar P, Otero-Espinar FJ and Fernández-Ferreiro A: Pharmacokinetics of intravitreal anti-VEGF drugs in age-related macular degeneration. Pharmaceutics 11: 365 , 2019.

28. Avery RL,Pearlman J,Pieramici DJ, Rabena MD, Castellarin AA, Nasir MA, Giust MJ, Wendel R and Patel A: Intravitreal bevacizumab (Avastin) in the treatment of proliferative diabetic retinopathy. Ophthalmology 113: 1695.e1-1695.e15, 2006.

29. Bakbak B, Ozturk BT, Gonul S, Yilmaz M and Gedik S: Comparison of the effect of unilateral intravitreal bevacizumab and ranibizumab injection on diabetic macular edema of the fellow eye. J Ocul Pharmacol Ther 29: 728-732, 2013.

30. Karaca C, Oner AO, Mirza E, Polat OA and Sahiner M: Bilateral effect of unilateral bevacizumab injection in retinopathy of prematurity. JAMA Ophthalmol 131: 1099-1101, 2013.

31. Malbin B, Patel HP, He Y, Le K and Lin X: Comparative eye effect of unilateral intravitreal bevacizumab, ranibizumab, and aflibercept for diabetic macular edema. J Vitreoretin Dis 3: 86-89, 2019.

32. Isildak H, Schwartz SG and Flynn HW Jr: Therapeutic effect of anti-VEGF for age-related macular degeneration in the untreated fellow eye. Case Rep Ophthalmol Med 2018: 8561895, 2018.

33. Wu Z and Sadda SR: Effects on the contralateral eye after intravitreal bevacizumab and ranibizumab injections: A case report. Ann Acad Med Singapore 37: 591-593, 2008.

34. Peyman M, Peyman A, Lansingh VC, Orandi A and Subrayan V: Intravitreal bevacizumab versus ranibizumab: Effects on the vessels of the fellow non-treated eye. J Curr Ophthalmol 31: 55-60, 2018.

35. Filip-Ciubotaru F, Manciuc C, Stoleriu G and Foia L: NADPH oxidase: Structure and activation mecanisms (Review). Note I Rev Med Chir Soc Med Nat Iasi 120: 29-33, 2016.

This work is licensed under a Creative Commons Attribution-NonCommercial-NoDerivatives 4.0 International (CC BY-NC-ND 4.0) License. 